\title{
Mild senile dementia of Alzheimer type: research diagnostic criteria, recruitment, and description of a study population
}

\author{
L BERG, ${ }^{*}$ CP HUGHES, ${ }^{*}$ LA COBEN, ${ }^{*}$ WL DANZIGER, ${ }^{*}$ RL MARTIN, $\dagger$ \\ J KNESEVICH†
}

From the Memory and Aging Project and the Department of Neurology and Neurological Surgery (Neurology)* and the Department of Psychiatry, $†$ Washington University School of Medicine, Saint Louis, Missouri, USA

SUMMARY Clinical investigations of senile dementia of the Alzheimer type require establishment of explicit clinical diagnostic criteria before histological confirmation is possible. Criteria for selection of mildly impaired subjects with senile dementia of Alzheimer type, free of other major disease, are proposed. Problems of recruitment of this select population for a longitudinal study are discussed. A study population with matched healthy control subjects has been enrolled and described. Short term follow-up has provided preliminary support for the diagnostic criteria.

The most frequent cause of dementia in persons over age 65 is senile dementia of the Alzheimer type (SDAT), multi-infarct dementia being much less common. $^{1-3}$ Increased awareness has led investigators to focus on SDAT and to search for means of identifying subjects in the less advanced stages, before the illness is complicated by effects of chronic debility and/or institutionalisation.

Establishing presumptive diagnostic criteria without resorting to histologic study of the brain is an essential goal of clinical investigation. The importance of this goal is underscored by the difficulties inherent in distinguishing among the many disorders leading to brain failure ${ }^{3-8}$ and by the dearth of valid information on aetiology, natural history, pathophysiology, and therapy of SDAT. Concurrent needs include a reliable means of quantifying the degree of dementia ${ }^{9}$ and a comparison of the effects of healthy aging with those of SDAT. The Dementia Study Group of Washington University has met frequently for several years to discuss and investigate topics related to dementia. ${ }^{10-17}$ The needs listed above led to the group to establish explicit clinical diagnostic criteria for SDAT and to initiate a longitudinal study of mild cases and healthy aging. In this paper is

Address for reprint requests: L Berg. MD., Department of Neurology and Neurological Surgery (Neurology), Washington University School of Medicine. Box 8111, 660 South Euclid Ave. St Louis, MO, 63110 USA.

Received 21 February 1982 and in revised form 5 May 1982. Accepted 15 July 1982 presented our experience in establishing a study population of SDAT and control subjects, both groups free of other major impairments.

\section{Methods}

Diagnostic criteria From discussions and experience of the Dementia Study Group emerged the following diagnostic criteria for SDAT:

I. Inclusion criteria (A, B and C must be present):

A. Sustained deterioration of memory in an alert subject, plus impairment in at least three of the following five cognitive abilities (explanatory statements are given in table 1): (1) orientation, (2) judgment and problem solving, (3) function in community affairs, (4) function in home and hobbies, (5) function in personal care.

B. Gradual onset and progression

C. Duration: six months or longer

II. Exclusion criteria (A, B and C must be absent):

A. Other neurologic disorders, ${ }^{13}{ }^{18}$ including Parkinsonism, Huntington's disease, communicating - hydrocephalus, progressive supranuclear palsy, infection, brain tumour, subdural haematoma, multiple sclerosis, stroke, multi-infarct dementia, seizure disorder, and brain trauma.

B. Psychiatric disorders, including primary affective disorder or major depression, schizophrenia, alcoholism or other substance abuse.

C. Other reversible dementias ${ }^{19}$ and other medical disorders that may reduce cognition, including overmedication, impaired function of lungs, heart, kidneys or liver, anaemia, hypothyroidism, vitamin $B_{12}$ or folate deficiency, malignancy and 
diabetes mellitus (if insulin-dependent or if more than mild in degree).

These criteria are designed to select a group of SDAT subjects, free of other disorders masquerâding as SDAT or complicating its effects. The criteria should be equally applicable to dementia of the Alzheimer type earlier in life.

Recognition of most of these disorders requires no further discussion, but some deserve special attention. Communicating (normal pressure) hydrocephalus is recognised by the clinical criterion of gait disorder preceding or accomanying the decline in intellect, and/or the CT criterion of severely dilated cerebral ventricles (including the temporal horns) with normal or absent cortical sulci. " is Subjects with SDAT, especially in its milder stages, are unlikely to have severe ventricular dilatation, unless communicating hydrocephalus is also present. ${ }^{2021}$

Multi-infarct dementia is recognised by the combination of long standing hypertension, history of strokes, transient ischaemic attacks or reversible ischaemic neurologic deficits, abrupt onset, stepwise deterioration, focal neurologic symptoms and signs, and pseudobulbar state. ${ }^{22}{ }^{23} \mathrm{We}$ elected not to exclude hypertensive subjects if they had no other indication of multi-infarct dementia and no other serious complication of hypertension.

A primary affective disorder (major depression), especially in the elderly, may lead to a clinical picture difficult to differentiate from dementia. ${ }^{+24}$ Subjects with a past history of psychiatric disorder and those with current depression diagnosable from a psychiatric interview were excluded. Four experienced clinicians (neurologists and psychiatrists, each certified by the American Board of Psychiatry and Neurology) excluded potential subjects who were depressed, as assessed either by overall clinical judgment or by research criteria. ${ }^{25}$ Special attention was given to complaints of somatic symptoms, malaise and/or poor thinking as possible indicators of depression in the elderly.

Recruitment Letters requesting the referral of subjects with mild SDAT were sent to local organisations of neurologists, psychiatrists and primary physicians. The request was also published in the bulletin of the St Louis Metropolitan Medical Society. Since there were few responses to these appeals, a series of discussions of the research program was initiated in local newspapers and on local television and radio. Healthy subjects responded to the same public announcements or were among those who had already willed their body to the School of Medicine. Each control subject was enrolled by being matched with a SDAT subject for age, sex, race and social position. This last variable was measured by the method of Hollingshead ${ }^{26}$ which includes level of education and which scores subjects from 1 to 5 , with 1 being the highest social class. Control subjects were in good health and were screened by the same exclusion criteria applied to the SDAT subjects. Recruitment was limited to noninstitutionalised subjects aged 64 to 81 . The subjects were recruited from a metropolitan region whose total population is approximately $2 \cdot 5$ million persons

Table 1 Clinical Dementia Rating (CDR). Impairments in each category are scored as $0 \cdot 5,1,2,3$ only according to cognitive impairment. (Reprinted by permission of the British Journal of Psychiatry)

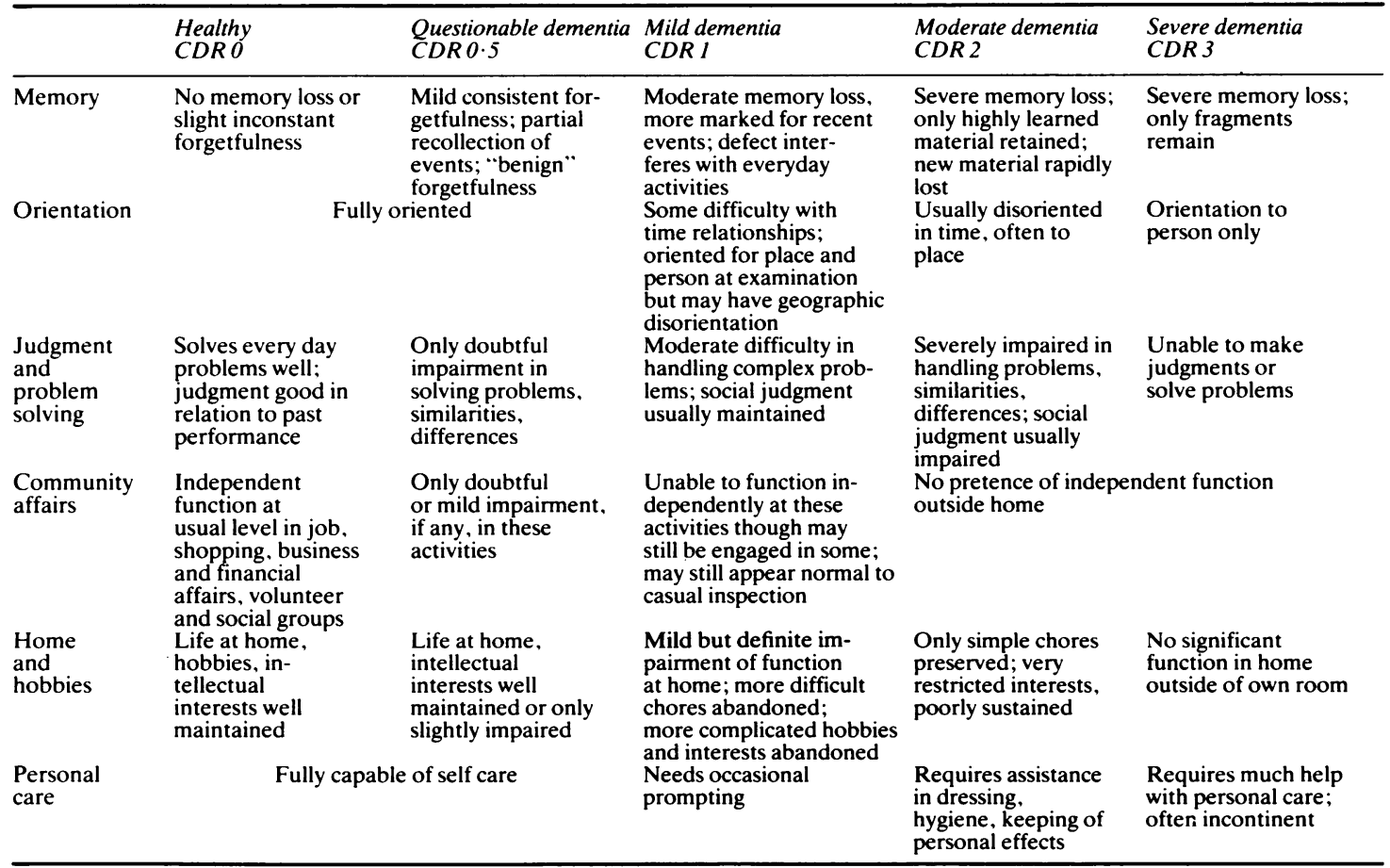


of mixed ethnic background. According to recent estimates (US Census Bureau) of the characteristics of those aged $64-84$ in this population, $62 \%$ are female and $87 \%$ are white. They comprise $12 \%$ of the total population. The average educational level is $9 \cdot 1$ years. The post-retirement income level is as at the poverty level for $6 \%$ of this elderly population, in the middle ranges for $79 \%$ and in the upper range $(\$ 15,000$ and above per year) for $15 \%$.

Clinical assessment A structured interview and examination, the Initial Subject Protocol (ISP), was developed in order to standardise the diagnosis of SDAT and to assess its severity. The ISP (copy available on request) includes a clinical interview with a collateral source who knows the subject well and an interview with the subject. Total time required is approximately 90 minutes. Information is gathered regarding the subject's family history, social, educational and cultural background, and medical, neurologic and psychiatric history. The collateral source is asked to rate the subject on memory function, orientation, and cognitive abilities in dealing with everyday function in home, recreational, and community activities. In each of these ratings a nine-point scale is used to compare the subject's current function with his or her past perfomance when well.

Within the mental status examination of the subject are tasks in memory, orientation, abstraction, calculation, judgment and problem solving. Answers are rated according to defined scoring standards. The ISP also includes several brief structured methods of clinical assessment employed by previous investigators. The Dementia Scale (DS) of Blessed et $a^{27}$ is a behavioural checklist rated according to information from the collateral source. It is scored from zero ("fully preserved capacity") to 28 ("extreme incapacity"). The Short Portable Mental Status Questionnaire (SPMSQ) of Pfeiffer ${ }^{2 \times}$ is composed of ten questions on orientation, memory and serial subtraction, with scores ranging from zero through ten errors. The Face Hand Test (FHT) ${ }^{29}$ is a performance measure unrelated to the intellectual background of the subject. It is administered and scored according to the method of Zarit et $a l^{3 \prime \prime}$, with scores ranging from zero ("normal") to 16 ("severe impairment"). The Hamilton Rating Scale for Depression (HRSD) ${ }^{31}$ is included to monitor manifestations of depression. Language function is assessed with verbal tasks from the Boston Diagnostic Aphasia Evaluation. ${ }^{32}$ The Aphasia Battery (AB) score ranges from zero ("no aphasia") to 35 ("severe aphasia"). A general physical examination and a complete neurologic examination are performed as part of the ISP, additional description of which has been published."

Staging of dementia versus healthy intellectual function Sufficient data are collected in the ISP to allow the interviewer to rate the subject in each of six cognitive and behavioural categories: memory $(\mathrm{M})$, orientation $(\mathrm{O})$, judgment and problem solving (JPS), community affairs (CA), home and hobbies $(\mathrm{HH})$, and personal care (PC). The rater considers the subject's function only in relation to cognitive ability and to the subject's past performance. Possible ratings in each category are $0,0 \cdot 5,1,2$, and 3 , which range from healthy (rating 0 ) to severe impairment (rating 3). The description of ratings in each category is given in table 1, which depicts the overall Clinical Dementia Rating (CDR). The method of deriving the CDR from the ratings in each of the six categories and a discussion of the reliability and validity of CDR are given elsewhere. ${ }^{9}$

Subjects are rated as healthy (CDR 0), mildly (CDR 1), moderately (CDR 2), or severely demented (CDR 3). The designation CDR 1 signifies that there has been sufficient intellectual deterioration to justify the diagnosis of mild SDAT, once the diagnostic criteria have been applied. Subjects who are neither clearly demented to that degree nor clearly healthy in intellectual function are assigned a rating of questionable dementia (CDR $0 \cdot 5$ ). Some of these CDR 0.5 subjects probably have early SDAT, too mild to be diagnosed, while others have "benign senescent forgetfulness" 3334 or other benign disorders. Healthy subjects (CDR Ú) still have good intellectual function in relation to their past performance. Our experience with healthy elderly subjects has led us to the following conclusions regarding their intellectual function: Healthy elderly can be forgetful in some everyday activities - for names and dates, parts of events, and rarely for events themselves, if the events are not major in their lives. Forgetfulness is not constant, does not interfere with everyday life, and is not a major concern to them. They may write notes as reminders, but the use of notes is not pervasive in their lives. Raters must compare the performance of subjects to that of healthy elderly persons whom the raters know. These conclusions are similar to those of Shader $e t a^{35}$. The criteria for exclusion of other disorders in the control subjects were the same as for the SDAT subjects.

All interviews were recorded on videotape for assessment by an independent reviewer. Both the interviews and the videotape reviews were performed by the same four experienced clinicians. In a previous pilot study of the ISP in 35 elderly subjects (some healthy and some demented), interrater reliability for determining the CDR was found to be $0 \cdot 89$. In the present longitudinal study of subjects with CDR $0,0.5$ and 1 , only six of 123 were eliminated because the interviewer and the reviewer disagreed in assigning the CDR.

In addition to the clinical assessment all recruited subjects were studied with blood counts and chemical analyses to exclude medical disorders detailed above. Subjects were entered into a longitudinal study of clinical status, psychometric performance, quantitative computed tomography (CT) of the brain, electroencephalography, and visual evoked potentials (VEP). Repeat clinical assessment was performed 6 to 12 months after entry into the study.

All studies and the procedures for obtaining informed consent thereto were approved by the Human Studies Committee of the Washington University School of Medicine.

\section{Results}

A total of 489 impaired potential subjects were eliminated for reasons given in table 2 . (The numbers total more than 489 because some persons were excluded for more than one reason.)

Forty three subjects with mild SDAT (CDR 1), 16 subjects with questionable SDAT (CDR 0.5), and 58 
Table 2 Reasons for exclusion of 489 impaired subjects. Subjects with glaucoma excluded because of risk incurred by dilating pupils for VEP study and because of effect of glaucoma on $V E P$

\begin{tabular}{lc}
\hline Re'asem & Number of subjects \\
\hline Outside age range & 101 \\
Dementia too severe (CDR 2 or 3) & 74 \\
Pstchiatric disorder (depression. etc.) & 59 \\
Cerebrovascular disease & 28 \\
Diabetes mellitus & 14 \\
Other serious medical and neurologic disorders & 55 \\
"Worried well. & 32 \\
Dementia only doubtful & 109 \\
(ilaucomat & 28 \\
Refused or unable to participate & 37 \\
\hline
\end{tabular}

Table 3 Characteristics of the study population

\begin{tabular}{|c|c|c|c|}
\hline$n$ & $\begin{array}{l}(I) R 0 \\
\text { is }\end{array}$ & $\begin{array}{l}C D R 0 \cdot 5 \\
16\end{array}$ & $\begin{array}{l}C D R I \\
43\end{array}$ \\
\hline $\begin{array}{l}\text { male female } \\
\text { age }\end{array}$ & $\begin{array}{l}28 / 30 \\
6+3-82.5 \\
71 \cdot 7 \pm 4.9\end{array}$ & $\begin{array}{l}8 / 8 \\
65 \cdot 2-79 \cdot 3 \\
71 \cdot 7 \pm 4 \cdot 1\end{array}$ & $\begin{array}{l}20 / 23 \\
63 \cdot 8-81 \cdot 2 \\
71 \cdot 4 \pm 5 \cdot()\end{array}$ \\
\hline lcars of education* & $\begin{array}{c}7-20 \\
12 \cdot 8=3 \cdot 5\end{array}$ & $\begin{array}{c}x-17 \\
12 \cdot 3 \pm 3 \cdot 1\end{array}$ & $\begin{array}{l}8-21 \\
12 \cdot 5 \pm 4 \cdot 1\end{array}$ \\
\hline wcial position * & $\begin{array}{l}1-4 \\
2 \cdot 9 \pm 1 \cdot 2\end{array}$ & $\begin{array}{l}1-5 \\
2 \cdot 8 \pm 1 \cdot 2\end{array}$ & $\begin{array}{l}1-5 \\
3 \pm 1 \cdot 2\end{array}$ \\
\hline hypertension & 13 & 1 & 11 \\
\hline
\end{tabular}

Expresied both as range and mean $\pm \mathrm{SD}$

Vumber of subjects with diastolic $B P=95 \mathrm{~mm} \mathrm{Hg}$

healthy control subjects (CDR ()) were enrolled over a 17 month period. All were Caucasian, although recruiting efforts were not restricted according to race. Further description of each group enrolled is given in table 3.

Among the 43 subjects with mild SDAT, the duration of illness at the time of recruitment ranged from one to nine years (mean, $3.4 \pm 1.7$ years), as estimated by the collateral source. The distribution of the data on duration is given in fig 1 . Variability in the patterns of ratings in each of the six cognitive and hehavioural categories can be seen in table 4 , which lists the number of subjects rated as healthy to severely impaired (0) to 3 ) in each category: memory $(\mathrm{M})$, orientation $(\mathrm{O})$, judgment and problem solving (JPS). community affairs (CA), home and hobbies $(\mathrm{HH})$, and personal care (PC). The grouped scores of the subjects on the AB, DS, SPMSQ, and FHT are compared in table 5. expressed in each instance as range in the upper entry and mean $\pm \mathrm{SD}$ in the lower entry. Despite the impairments in intellectual function and duration of illness, the subjects with mild SDAT were all living in the community and were able to complete the psychometric battery and VEP testing.

One hundred sixteen subjects were reassessed by clinical interview and assigned a CDR 12 months after entry. The original CDRs on these 116 subjects were

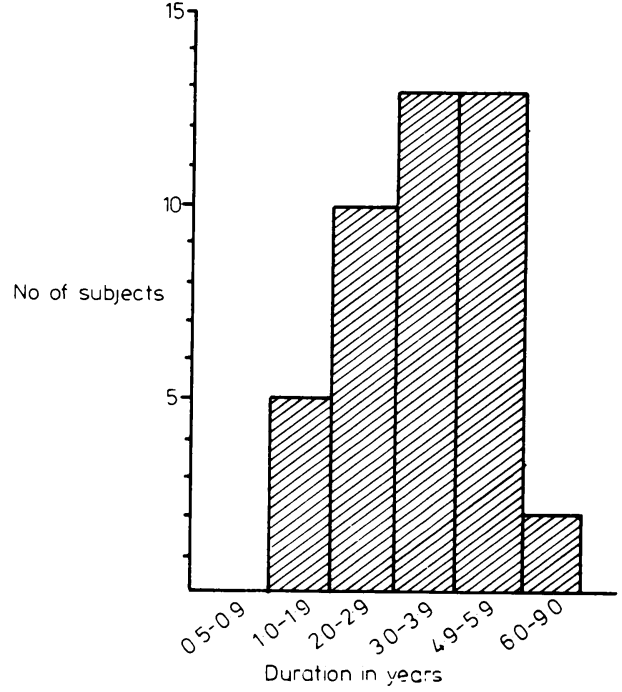

Fig 1 Duration of illness at time of entry in 43 subjects with mild $S D A T(C D R$ l)

as follows: 58 were CDR 0,16 were CDR $0 \cdot 5$, and 42 were CDR 1 . The 58 subjects with CDR 0 at entry were still rated as healthy on follow-up. Of 16 subjects with CDR 0.5 at entry, one was rated CDR 0 , eight were rated $0 \cdot 5$, and seven were rated CDR 1 on follow-up. The 42 subjects with mild SDAT (CDR 1) on entry had the following results on follow-up: None had improved to CDR 0 or $0 \cdot 5 ; 21$ were still at CDR 1; 16 had progressed to CDR 2, and five to

Table 4 Ratings for the three groups of subjects in each of the six categories $(M, O, J P S, C A, H H, P C)$. Compare table 1 for description of the ratings

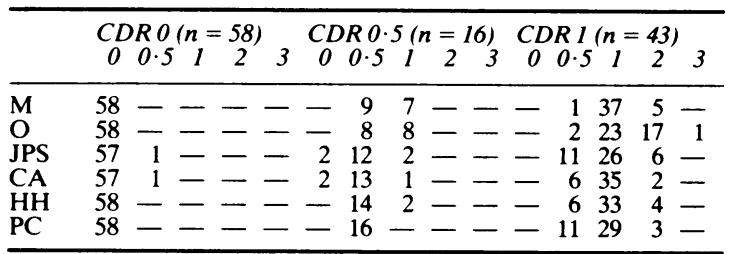

Table 5 Scores of the subjects on other clinical assessments

\begin{tabular}{lccc}
\hline & $C D R O$ & $C D R O \cdot 5$ & $C D R I$ \\
\hline $\mathrm{AB}$ & $0-2$ & $0-2$ & $0-21$ \\
& $0 \cdot 2 \pm 0 \cdot 5$ & $0 \cdot 2 \pm 0 \cdot 5$ & $4 \cdot 2 \pm 5 \cdot 4$ \\
DS & $0-4 \cdot 5$ & $0 \cdot 5-7 \cdot 0$ & $1-15 \cdot 5$ \\
& $0 \cdot 2 \pm 0 \cdot 7$ & $3 \cdot 1 \pm 2 \cdot 0$ & $5 \cdot 1 \pm 3 \cdot 1$ \\
SPMSQ & $0-2$ & $0-5$ & $1-10$ \\
& $0 \cdot 4 \pm 0 \cdot 6$ & $1 \cdot 8 \pm 1 \cdot 7$ & $5 \cdot 7 \pm 2 \cdot 2$ \\
FHT & $0-11$ & $0-15$ & $0-16$ \\
& $0 \cdot 8 \pm 2 \cdot 0$ & $2 \cdot 5 \pm 4 \cdot 2$ & $7 \cdot 3 \pm 6 \cdot 4$ \\
\hline
\end{tabular}


CDR 3. Four deaths have occurred. Three of the original CDR 1 subjects died (16, 26 and 27 months after entry, respectively) with Alzheimer's disease confirmed in all three at autopsy. One of the CDR 0.5 subjects who remained at that stage for 12 months died of a cerebral haemorrhage, but permission for postmortem examination was withheld.

Neither major depressions, nor other disorders became evident in any of the subjects. Psychometric results (analysed in another publication) in the CDR 1 subjects were all consistent with intellectual impairment. Preliminary quantitative $C T$ analyses are discussed elsewhere ${ }^{36}$. Of importance here is the fact that communicating hydrocephalus, multiple infarcts, and mass lesions were not found.

\section{Discussion}

The diagnostic criteria for SDAT proposed here appear at present to be satisfactory for the goals of the longitudinal clinical investigations underway. So far the diagnosis of SDAT has not been shown to have been made in error. However, the conclusions must be tentative since clinical follow-up of this study population is brief and only three SDAT subjects have died, albeit with confirmation of the diagnosis.

The approach of adopting inclusion and exclusion diagnostic criteria has been used formally or informally by others. ${ }^{37-40}$ In keeping with the principle that multiple diseases accumulate with aging, subjects with SDAT often have additional cerebral disorders, such as coexistent multi-infarct state ${ }^{123}$ and Parkinson's disease. ${ }^{+1+2}$ For some investigations (epidemiology, heredity) of SDAT, the inclusion of "mixed" cases will be appropriate, whereas other investigations, such as the one initiated here (natural history, pathophysiology), require more restrictive criteria to select subjects with "pure" SDAT. For some purposes it may be advisable to exclude subjects on medication or those with hypertension or atherosclerosis of coronary or peripheral circulation, as Isaacs $^{39}$ has suggested. Those goals are not easily met. In order to obtain our sample of 43 subjects with SDAT, we accepted those on minimal dosages of medication. Eleven subjects with mild hypertension were enrolled. Hypertension is known to be a risk factor for cerebrovascular disease and may be associated with some effect on intellectual function, ${ }^{43}$ but there is insufficient evidence on this latter point. The 11 subjects with hypertension had no indication of ischaemic disease of the brain. Their modified Ischaemic Score ${ }^{23}$ was less than five in each case. The use of a detailed history from a collateral source, the exclusion of persons with a past history of psychiatric disorder, and the careful attention to depression have reduced the difficulties reported by others ${ }^{578}$ in the differential diagnosis of dementia and nonorganic disorders.

Performance on a psychometric battery was not included as a diagnostic criterion, because it is to be considered as a variable independent of the clinical assessment in the longitudinal study of healthy aging versus SDAT. CT cannot be used at present in the differentiation of SDAT from normal aging, ${ }^{17}$ but is important in the exclusion of other disorders. Quantitative CT techniques still under investigation may prove to be valuable. ${ }^{36}$

Our strict criteria made recruitment of 43 subjects with mild SDAT difficult in a metropolitan area of approximately 2.5 million persons. Of course, many more subjects were available who had more advanced SDAT, many of whom are institutionalised. From the families of our subjects and from our contacts with the medical community at large, we have learned that the following factors impede efforts at the recruitment of subjects with mild SDAT: (1) willingness of many families to tolerate gradual mental deterioration without insisting on intervention ("It's just old age"), (2) failure of many physicians to recognise mild dementia in the elderly, (3) negative impact of the term, dementia, (4) apathy toward research efforts in SDAT, (5) strict research diagnostic criteria, (6) frequency of other disorders which mimic SDAT, (7) coexistence of other disorders that influence cognitive function and therefore complicate the analysis of SDAT alone, (8) reluctance on the part of some physicians, some subjects, and some families to participate in a research effort that does not promise the hope of an immediate reward, such as a "promising treatment" for SDAT.

Our experience suggests that investigators must announce their programs to the public in order to be successful. Recruitment results improved when the name was changed from Dementia Study Group to Memory and Aging Project. The newly established Alzheimer's Disease and Related Disorders Association will help, but the search for subjects with SDAT, defined by research criteria, free from other major disease, and mild enough that they can still live in the community, will remain difficult. The recruitment technique for SDAT subjects depended mainly on responses from the pubic to our appeals through the media. Families or close friends encouraged the subjects to participate. Among the healthy control subjects, many responded to the same public announcements and others were recruited from among those who had already willed their body to the School of Medicine. There are intangibles such as motivation and interest in research and other academic pursuits which may well differ between the SDAT and control groups. The same is true of most clinical research projects in which one group comes for help and 
another is recruited from among the healthy. A community-wide survey for mild SDAT and control subjects would have advantages but motivational differences would still exist. These SDAT and control subjects differ from the general population of the elderly in this region in being more educated $(12.5 \mathrm{vs}$ $9 \cdot 1$ years). Fifty-three per cent of the SDAT subjects were female, as compared to $62 \%$ females among the total community elderly. It is difficult to compare Hollingshead social positions with income levels of the general elderly population, but our subjects had a mean social position in the middle range. The distribution of social position among the community elderly is not available, nor are income levels among our subjects. One has the impression that our subjects have a distribution of income levels higher than that of the general elderly in the community, in keeping with the higher educational attainment.

The present sample of 43 subjects with mild SDAT was selected by restrictive criteria for purposes of a longitudinal study. Though they were still at a mild stage of the disorder (CDR 1), the duration of illness ranges from one to nine years. Data on duration of SDAT must be interpreted with caution in view of the well-known difficulty in dating the gradual onset of the disorder, but the variability in rate of progression is evident. A variability in the degree of impairment in the six cognitive categories (table 4) is also to be noted. A summary comparison of our lengthy clinical assessment (ISP, CDR) with briefer instruments ( $\mathrm{AB}, \mathrm{DS}, \mathrm{SPMSQ}, \mathrm{FHT})$ is given in table 5. The occurrence of healthy or near-healthy scores on each of these other instruments among our CDR 1 subjects attests to the mild stage of their SDAT. The relative merits of brief versus lengthy instruments are of considerable practical importance and will be discussed in later publications.

Twelve months after entry into the study, healthy controls (CDR 0 ) remained well. As expected, some subjects with mild SDAT (CDR 1) remained at the same stage, while others progressed to more severe stages, but none improved. It was anticipated that subjects with only questionable dementia (CDR $0 \cdot 5$ ) would represent a heterogenous diagnostic group whose course would vary. The findings that one of these was judged to be intellectually normal on follow-up, that some remained in the questionable group, and that others progressed to definite, mild SDAT (CDR 1) verify the original assumption. The predictive value and interrelationships of the details in clinical assessment, psychometric results, CT, EEG and VEP are being analysed and will be the subject of future reports.

The clinical results on brief follow-up and the impairments found on the psychometric battery provide only preliminary evidence in our long term efforts to.validate the clinical diagnostic criteria for SDAT. Final proof must await postmortem study of the brain, but it is to be expected that the great majority of SDAT subjects so diagnosed will prove to have Alzheimer's disease, with a few having less common disorders, such as Pick's disease, progressive subcortical gliosis, or unusual vascular diseases of the brain, any of which may masquerade during life as SDAT. Other investigators are encouraged to undertake prospective studies of diagnostic criteria applicable to mild SDAT.

This work was supported in part by Grant \#MH31054 from the National Institute of Mental Health. We are grateful to Dr William M Landau and to Helen Gavigan, Emily LaBarge, Dorothy Edwards and other members of the Memory and Aging Project, all of whom helped make this work possible. Patti Vessell assisted in preparation of the manuscript. We are particularly indebted to the subjects and their families for their dedication and cooperation.

\section{References}

1 Tomlinson BE, Blessed G, Roth M. Observations on the brains of demented old people. J Neurol Sci 1970; 11:205-42.

2 Jellinger K. Neuropathological aspects of dementias resulting from abnormal blood and cerebrospinal fluid dynamics. Acta Neurol Belg 1976;76:83-102.

${ }^{3}$ Wells CE. Chronic brain disease: an overview. Am J Psychiatry 1978;135:1-12.

+ Post F. Dementia, depression and pseudodementia. In: Benson DF, Blumer D, eds. Psychiatric Aspects of Neurologic Disease. New York: Grune \& Stratton 1975:99-120.

5 Nott PN, Fleminger JJ. Presenile dementia: the difficulties of early diagnosis. Acta Psychiatr Scand 1975;51:210-7.

- Todorov AB; Go RCP, Constantinidis J, Elston RC. Specificity of the clinical diagnosis of dementia. $J$ Neurol Sci 1975;26:81-98.

7 Bergmann K. Prognosis in chronic brain failure. Age Ageing 1977;6(Suppl):61-6.

8 Ron MA, Toone GK, Garralda ME, Lishman WA. Diagnostic accuracy in presenile dementia. $\mathrm{Br} J$ Psychiatry 1979;134:161-8.

9 Hughes CP, Berg L, Danziger WL, Coben LA, Martin RL. A new clinical scale for the staging of dementia. $\mathrm{Br}$ J Psychiatry 1982;140:566-72.

10 Hughes CP, Myers FK, Smith K, Torack RM. Nosologic problems in dementia. Neurology (Minneap) 1973; 23:344-51.

"Gado MH, Coleman RE, Lee KS, Mikhael MA, Alderson PO, Archer CR. Correlation between computerized transaxial tomography and radionuclide cisternography in dementia. Neurology (Minneap) 1976;26:555-60.

12 Grubb RL, Raichle ME, Gado MH, Eichling JO, 
Hughes CP. Cerebral blood flow, oxygen utilization and blood volume in dementia. Neurology (Minneap) 1977;27:905-10.

13 Hughes CP. The differential diagnosis of dementia in the senium. In: Nandy $\mathrm{K}$, ed. Senile Dementia: A Biomedical Approach. New York/Amsterdam: Elsevier/ North-Holland 1978;201-8.

14 Gado MH, Hughes CP. Computerized tomography scan in the diagnosis and management of senile dementia. See ref $13 ; 223-36$.

15 Hughes CP, Siegel BA, Coxe WS, Gado MH, Grubb RL, Coleman RE, Berg L. Adult idiopathic communicating hydrocephalus with and without shunting. $J$ Neurol Neurosurg Psychiatry 1978;41:961-71.

${ }^{16}$ Clinicopathologic Conference. Dementia and the problems of aging. Am J Med 1979;67:307-16.

17 Hughes CP, Gado M. Computed tomography and aging of the brain. Radiology 1981;139:391-6.

18 Haase GR. Diseases presenting as dementia. In: Wells CE, ed. Dementia ed 2. Philadelphia: Davis, 1977; 27-68.

19 Besdine RW, Brody JA, Butler RN, Duncan LE Jr, Jarvik L, Libow L. Senility reconsidered: treatment possibilities for mental impairment in the elderly. JAMA 1980;244:259-63.

${ }^{20}$ Sohn RS, Siegel BA, Gado M, Torack RM. Alzheimer's disease with abnormal cerebrospinal fluid flow. Neurology (Minneap) 1973;23:1058-65.

${ }^{21}$ Katzman R. Normal pressure hydrocephalus. In: Wells CE, ed. See ref 18;69-92.

22 Hachinski VC, Iliff LD, Zilkha E, DuBoulay GH, McAllister VL, Marshall J, Russell RWR, Symon L. Cerebral blood flow in dementia. Arch Neurol 1975; 32:632-37.

23 Rosen WG, Terry RD, Fuld PA, Katzman R, Peck A. Pathological verification of ischemic score in differentiation of dementias. Ann Neurol 1980;7:486-8.

24 Wells CE. Pseudodementia. Am J Psychiatry 1979;136: 895-900.

${ }^{25}$ Feighner JP, Robins E, Guze SB, Woodruff RA, Winokur G, Munoz R. Diagnostic criteria for use in psychiatric research. Arch Gen Psychiatry 1972;26: 57-63.

${ }^{26}$ Hollingshead AB. Two Factor Index of Social Position. New Haven, 1957.

27 Blessed G, Tomlinson BE, Roth $M$. The association between quantitative measures of dementia and of senile change in the cerebral grey matter of elderly subjects. Br J Psychiatry 1968;114:797-811.

${ }^{28}$ Pfeiffer E. A short portable mental status questionnaire for the assessment of organic brain deficit in elderly patients. J Am Geriatr Soc 1975;23:433-41.

29 Fink M, Green MA, Bender MB. The face-hand test as a diagnostic sign of organic mental syndrome. Neurology (Minneap) 1952;2:46-58.

${ }^{30}$ Zarit SW, Miller NE, Kahn RL. Brain function, intellectual impairment and education in the aged. $J$ Am Geriatr Soc 1978;26:58-66.

${ }^{31}$ Hamilton M. Development of a rating scale for primary depressive illness. Br J Soc Clin Psychol 1967;6: 278-96.

32 Goodglass H, Kaplan E. The Assessment of Aphasia and Related Disorders. Philadelphia: Lea \& Febiger, 1972.

${ }^{33} \mathrm{Kral}$ VA. Senescent forgetfulness: benign and malignant. Canad Med Assoc J 1962;86:257-60.

${ }^{34}$ Kral VA. Benign senescent forgetfulness. In: Katzman $\mathrm{R}$, Terry RD, Bick KL, eds. Alzheimer's Disease: Senile Dementia and Related Disorders. New York: Raven, 1978:47-51.

35 Shader RI, Harmatz JS, Tammerk H-A. Towards an observational structure for rating dysfunction and pathology in ambulatory geriatrics. In: Meier-Ruge W, ed. CNS Aging and its Neuropharmacology: Experimental and Clinical Aspects. Basel: Karger F, 1979, 153-68. (Interdiscipl Topics Geront 1979;15:153-68).

${ }^{36}$ Gado MH, Hughes CP, Danziger W, Chi D, Jost G, Berg L. Volumetric measurements of the cerebrospinal fluid spaces in subjects with dementia and in controls. Radiology 1982; in press.

${ }^{37}$ Katzman R, Karasu TB. Differential diagnosis of dementia. In: Fields WS, ed. Neurological and Sensory Disorders in the Elderly. New York: Stratton, 1975; 103-34.

${ }^{38}$ Roth M. Diagnosis of senile and related forms of dementia. In: Katzman R, Terry RD, Bick KL, eds. See ref $34 ; 71-85$.

39 Isaacs B. The evaluation of drugs in Alzheimer's disease. Age Ageing 1979;8:1-7.

${ }^{40}$ Eisdorfer C, Cohen D. Diagnostic criteria for primary neuronal degeneration of the Alzheimer's type. J Fam Pract 1980;11:553-57.

4) Hakim AM, Mathieson G. Dementia in Parkinson disease: a neuropathologic study. Neurology (Minneap) 1979;29:1209-14.

42 Boller F, Mizutani T, Roessman U, Gambetti P. Parkinson disease, dementia, and Alzheimer disease: clinicopathological correlations. Ann Neurol 1980; 7:329-35

43 Wilkie F, Eisdorfer C. Intelligence and blood pressure in the aged. Science 1971;172:959-62. 